\title{
Fresh and good news
}

\section{NOVAS E BOAS NOTÍCIAS}

\author{
Carlos V. Serrano JR. ${ }^{1}$
}

In the last edition of 2014, we used this very section to discuss the Journal of the Brazilian Medical Association's (Ramb, Revista da Associação Médica Brasileira) new pathways, through an editorial in which we presented plans aiming at its consolidation among the country's most relevant scientific publications.

Today, almost a year later, we have something to celebrate. There has been an increase in Ramb's impact factor: from 0.915, as measured in 2013, to 0.933 in 2014, a result that places Ramb among the 20 most cited Brazilian journals. This information was reported by the Journal Citation Reports (JCR) and published by the ISI WEB of Knowledge portal page on June 18, based on citation statistics of 2014. This is the second consecutive year that Ramb grows in impact factor. In 2012, Ramb's impact factor calculated using the same criteria adopted by the JCR was 0.771 , that is, Ramb has increased its number of citations by 0.162 in just two years.

The impact factor is known to be a measure that demonstrates the average number of citations of scientific articles published in a given journal, serving as a parameter to evaluate and compare journals from a common area. The higher the impact factor of a journal, the better its chances of having an article cited. In addition to the JCR (Science Citation), which assesses journals, Ramb is also included in the SJR SCImago (Journal \& Country Rank, Scopus/Elsevier database), with 0,267 (2013) indicator value, and ranked as Qualis/Capes category B2. It is also indexed on the Lilacs, PubMed (Medline), Scopus and SciELo databases.

This result is important for Ramb and shows that we are on track towards increasing its reach year after year. We believe that strategies such as the plan to issue a monthly journal, to prepare special themed editions, reformulate the current proofreading process and change the sub- mission process to give more flexibility to the development of articles can help to raise even more this impact factor.

Thus, since the beginning of August, Ramb has a new article submission mechanism. It is called ScholarOne, a platform certified by SciELO through a partnership with Thomson Reuters, one of the most reputable scientific information platforms, employed by journals throughout the world.

The advantages that ScholarOne provides authors and us, editors administratively, greatly optimizing the flow of articles, will allow Ramb to gain more agility, favoring all.

The ScholarOne is currently used by over 500 institutions, 3,400 journals worldwide, supporting over 13 million users. In addition to features that significantly reduce time in the flowchart of submissions, it offers plagiarism detection, automated citation hyperlink to PubMed, sending of multimedia files, and online database FAQ, allowing research various subjects for basic submission tasks.

Access to the platform is done through the new Ramb website (www.ramb.org.br), launched last May. By clicking on submit article, in the main menu, the author will be redirected to the ScholarOne platform. In addition to this facility, the new website is more up-to-date, with a sleek enjoyable look, as well as quite objective. It features search tools to previous editions of Ramb, which from this point on will be available online only, together with all the material made available to date by the SciELo. There is also a section to present news, links to other clinical guidelines produced by the Brazilian Medical Association (AMB, Associação Médica Brasileira) and specialties, norms for the publication of journal supplements, norms to write articles, and online access for article submission.

We hope to return soon to this section with fresh and good news, not only for Ramb, but for the Brazilian scientific community that believes in our work. 